\title{
The frequency of agoraphobia and the comorbidity of major depressive disorder in panic disorder
}

Accepted: 21/1/2012

\begin{tabular}{l}
\hline Diyar Hussain Tahir* \\
Abstract \\
Background and objectives: Panic disorder (PD) is a common disabling psychiatric con- \\
dition that has a considerable impact on the quality of life. This study was done to estimate \\
the frequency of agoraphobia and the comorbidity of major depressive disorder (MDD) in \\
PD, with related sex difference.
\end{tabular}

Methods: A cross sectional descriptive study, was done on patients who consulted a private psychiatric clinic for features of PD, in Erbil city from August 2009 to August 2010. A convenient sample of 118 patients, 73 females and 45 males, having PD with or without agoraphobia were taken after giving their informed verbal consent. All patients were checked for the presence of MDD. The diagnoses were done clinically, and then checked according to the diagnostic and statistical manual of mental disorders, 4th edition, text revision (DSM-IV-TR).

Results: Mean age of PD with or without agoraphobia was 31.1 years. Female to male ratio was 1.6/1. Mean age at onset was 26.3 years. Mean duration of illness was 4.4 years. Patients having PD without Agoraphobia were $81.4 \%$, while having PD with agoraphobia were $18.6 \%$ in which the males $(20 \%)$ affected more than females $(17.8 \%)$. The comorbidity rate of MDD (mild to severe degree) in PD was $61 \%$ with higher males $(68.9 \%)$ than females $(57.5 \%)$.

Conclusion: The majority of patients with PD in our sample had a comorbid MDD. Early detection and management of PD is necessary to reduce complications and improve their quality of life.

Keywords: Panic disorder, agoraphobia, comorbidity, depression

\section{Introduction}

Panic disorder (PD) is a common disabling psychiatric illness that has a considerable impact on the quality of life. It impairs the social, family and working lives of sufferers at a time when they should make the greatest contribution to society. It leads to overutilization of medical facilities in futile efforts to find a physical cause for their symptoms. Frequent comorbid psychiatric conditions, most notably depression and other anxiety disorders complicate the clinical presentation, exacerbating individual disability and increasing the economic burden to society. ${ }^{1} \mathrm{PD}$ has a life time prevalence of $1.5-4 \%$ of population, ${ }^{2}$ but it is often undia- gnosed and untreated. ${ }^{3}$ The longer length of time from onset of panic to first treatment is associated with higher rates of comorbidity at first psychiatric treatment contact and less favorable treatment outcomes. ${ }^{4}$ Panic attack is the hallmark of PD. It is a feeling of overwhelming fear that can be defined as a specific, discrete type of anxiety, characterized by an abrupt onset and rapid crescendo peak of prominent autonomic symptoms, often seeming to come 'out of the blue. ${ }^{5}$ While to describe the state as PD, it must include panic attacks, anticipatory anxiety for at least one month about the possibility of having a panic attack, phobic symptoms and functional disability in daily life. ${ }^{1,6}$ Agoraphobia

\footnotetext{
*Department of Psychiatry, College of medicine., Hawler Medical University, Erbil, Iraq.
} 
is strongly linked to PD. Agoraphobia is an avoidance behavioral response to panic attacks that attempts to reduce the frequency of attacks, where the patients may come to associate panic attacks with specific situations or settings, these situations or settings are then avoided. Common situations in which panic attacks occur are those where the patient feels crowded, confined, and without an easy exit, or being in novel situations away from sources of support such as a spouse. Although the goal of this avoidance behavior is to reduce the frequency of attacks, it may result in a restricted lifestyle and impairment in occupational and interpersonal functioning. ${ }^{7}$ The term 'comorbidity', coined by Feinstein, is now widely used to refer to the greater than coincidental association of two conditions in the same individual. ${ }^{8}$ Comorbidity between PD and depression is one of the most strongest psychiatric comorbidities, ${ }^{9}$ and the single strongest anxiety-mood episode comorbidity in both treatment sample, $^{10}$ and general population sample. ${ }^{11}$ Data from several epidemiologic studies show that the majority of individuals who experience a panic attack will also have an episode of major depression during their lifetime. ${ }^{12,13}$ The likelihood of this cooccurrence is even stronger among those who meet the full criteria for PD. ${ }^{14} \mathrm{~A}$ great number of studies indicate that this specific comorbidity when compared to the non comorbid cases, they determine: increased symptom severity, ${ }^{15}$ an unfavorable outcome or a more chronic illness, ${ }^{16} \mathrm{de}-$ creased professional and social functioning, ${ }^{17}$ and a reduced therapeutic response and compliance. ${ }^{18}$ The risk of suicidal behavior associated with comorbid panic and depression also far exceed those associated with either disorder alone. ${ }^{19}$ In addition, numerous studies have shown that PD and depression are each associated with similar common risk factors for psychopathology, such as low socioeconomic status, childhood abuse, and psychiatric comorbidity, suggesting possible common environmental etiologic links. ${ }^{20,21}$ Moreover, there are data to suggest that treating panic attack associated with decreased likelihood of the onset of major depressive disorder (MDD) among adults, ${ }^{22}$ providing additional evidence of a link. In particular, the first line recommended psychopharmacologic treatment by selective serotonin reuptake inhibitors for both panic and depression is the same, suggesting a common neurobiological mechanisms. ${ }^{23,24}$ Finally, cognitive behavioral therapy and other psychotherapeutic interventions have proven efficacy with both PD and MDD. ${ }^{25-26}$

Aims of the study:

1- To estimate the frequency of agoraphobia in PD and the related sex difference.

2- To estimate the comorbidity rate of MDD in PD and the related sex difference.

\section{Methods}

A cross sectional descriptive study was collected from patients who consulted a private psychiatric clinic for features of PD, in Erbil city from August 2009 to August 2010. A convenient sample of 118 patients, 73 females and 45 males, having PD with or without agoraphobia were enrolled in this study after taking their informed verbal consent. All patients were checked for the presence of MDD. The diagnoses of PD without agoraphobia, PD with agoraphobia and MDD were done clinically by a specialist psychiatrist according to the diagnostic criteria for PD without agoraphobia, PD with agoraphobia and MDD depending on the diagnostic and statistical manual of mental disorders, 4th edition, text revision (DSM-IV-TR). 6,27 The patients with MDD were classified to Mild, Moderate, Severe without psychotic features and Severe with psychotic features MDD according to the DSM-IV-TR . ${ }^{27}$ Patients with primary depression, normal bereavement, history of manic or hypomanic episodes, history of schizophrenia and the related disorders, alcohol and drug dependence, and any physical illness were excluded from the study. All informations including data concerning age, sex, marital status, occupation, age of onset and duration of illness of 
PD were taken through a direct interview. Statistical analyses in form of range, mean and standard deviation were applied by using Microsoft excel program.

\section{Results}

The Range of age of PD with or without agoraphobia was 34 years (17-51), with a Mean of 31.1 years \pm SD 7.6. The female to male ratio was $1.6 / 1$. Married patients were $78 \%$. Regarding occupation; $84.4 \%$ of the males were employed, while $74 \%$ of the females were housewives. The Range of age of onset of PD with or without agoraphobia was 31years (16 - 47), with a Mean of 26.3 years \pm SD 6.3 , while the Range of duration of illness was 7.3 years $(0.2$ 7.5), with a Mean of 4.4 years \pm SD 2.1.

Patients having PD without Agoraphobia were $81.4 \%$, while having PD with agoraphobia were $18.6 \%$. The men $(20 \%)$ were more likely than women $(17.8 \%)$ to have PD with agoraphobia Table (1). The comorbidity rate of MDD in PD with or without agoraphobia was $61 \%$; Mild MDD was $21.2 \%$, Moderate MDD was $33.9 \%$ and Severe without psychotic features MDD was $5.9 \%$. comorbidity was higher in males $(68.9 \%)$ than females $(57.5 \%)$, as shown in Table (2).

Table 1: Distribution of PD with or without Agoraphobia according to age group and sex.

\begin{tabular}{|c|c|c|c|c|c|c|}
\hline \multirow{2}{*}{$\begin{array}{l}\text { Age } \\
\text { group } \\
\text { (years) }\end{array}$} & \multirow{2}{*}{$\begin{array}{l}\text { PD without } \\
\text { Agoraphobia } \\
\text { Male } \\
\text { No. (\%) }\end{array}$} & \multirow[b]{2}{*}{$\begin{array}{l}\text { Female } \\
\text { No. }(\%)\end{array}$} & \multicolumn{2}{|c|}{ PD with Agoraphobia } & \multirow{2}{*}{$\begin{array}{l}\text { Total PD } \\
\text { Male } \\
\text { No. (\%) }\end{array}$} & \multirow[b]{2}{*}{$\begin{array}{l}\text { Female } \\
\text { No. (\%) }\end{array}$} \\
\hline & & & $\begin{array}{l}\text { Male } \\
\text { No. (\%) }\end{array}$ & $\begin{array}{l}\text { Female } \\
\text { No. (\%) }\end{array}$ & & \\
\hline $15-24$ & $11(24.4)$ & $17(23.3)$ & $2(4.4)$ & $4(5.5)$ & $13(28.9)$ & $21(28.8)$ \\
\hline $25-34$ & $17(37.8)$ & $29(39.7)$ & $6(13.3)$ & $8(11)$ & $23(51.1)$ & $37(50.7)$ \\
\hline $35-44$ & $7(15.6)$ & $12(16.4)$ & $1(2.2)$ & $1(1.4)$ & $8(17.8)$ & $13(17.8)$ \\
\hline $45-54$ & $1(2.2)$ & $2(2.7)$ & $0(0.0)$ & $0(0.0)$ & $1(2.2)$ & $2(2.7)$ \\
\hline Total & $36(80)$ & $60(82.2)$ & $9(20)$ & $13(17.8)$ & $45(100)$ & $73(100)$ \\
\hline
\end{tabular}

Table 2: Distribution of MDD in PD according to sex.

\begin{tabular}{lcclll} 
Sex & $\begin{array}{l}\text { Mild MDD } \\
\text { No. (\%) }\end{array}$ & $\begin{array}{l}\text { Moderate } \\
\text { MDD } \\
\text { No. (\%) }\end{array}$ & $\begin{array}{l}\text { Severe MDD } \\
\text { without } \\
\text { psychotic } \\
\text { features } \\
\text { No. (\%) }\end{array}$ & $\begin{array}{l}\text { Severe MDD } \\
\text { with } \\
\text { psychotic } \\
\text { features } \\
\text { No. (\%) }\end{array}$ & $\begin{array}{l}\text { Total MDD } \\
\text { in PD } \\
\text { No. (\%) }\end{array}$ \\
\hline Male & $11(24.4)$ & $17(37.8)$ & $3(6.7)$ & $0(0.0)$ & $31(68.9)$ \\
Female & $14(19.2)$ & $23(31.5)$ & $4(5.5)$ & $0(0.0)$ & $42(57.5)$ \\
Total & $25(21.2)$ & $40(33.9)$ & $7(5.9)$ & $0(0.0)$ & $72(61.0)$
\end{tabular}


Table 3: Distribution of PD according to age of onset and marital status.

\begin{tabular}{llll} 
Age of onset (years) & No. (\%) & Marital status & No. (\%) \\
\hline $15-24$ & $40(33.9)$ & Single & $22(18.6)$ \\
$25-34$ & $65(55.1)$ & Married & $92(78)$ \\
$35-44$ & $12(10.2)$ & Widowed & $3(2.5)$ \\
$45-54$ & $1(0.8)$ & divorced & $1(0.8)$ \\
Total & $118(100)$ & Total & $118(100)$
\end{tabular}

\section{Discussion}

The mean age of patients with PD with or without agoraphobia in this study was 31.1 years, which is similar to Battaglia et al study (31.9 years). ${ }^{28}$ and relatively close to Fleet et al study (36.5 years). ${ }^{29}$ The patients age were mostly between 15 to 44 years. Only three cases were from the 4554 years age group and no cases were found above that range. These findings are similar to Yates study in $2009^{7}$ and to Andrade et al study, ${ }^{30}$ and this may reflect a tendency for PD to abate over time, and may be an effect of increased mortality in PD with age. The female to male ratio was $1.6 / 1$, and this is concordant to Fleet et al study $(1.7 / 1)^{29}$ and to Felicia et al study $(1.99 / 1) .{ }^{31}$ Most of the patients were married $(78 \%)$ which is distant from Andrade et al study (41.7), ${ }^{30}$ but close to Felicia et al study $(72.2 \%){ }^{31}$. The mean age of onset of PD in this study was 26.3 years \pm SD 6.3, which is relatively close to Battaglia et al study (22.7 years). ${ }^{28}$ The mean duration of illness at interview time was 4.4 years \pm SD 2.1, while in Battaglia et al study it was 9.2 years $^{28}$ and in Felicia et al study it was 9.6 years ${ }^{31}$, where the natural history of PD is consistent with that of a chronic illness. ${ }^{7}$ Rate of PD with agoraphobia in our study was $18.6 \%$, which is lower than what was shown by Yates study who reported that one-third to one-half of patients with $P D$ also met the criteria for agoraphobia. This lower rate of PD with agoraphobia in our study may be related to the stronger social network and support in our society than in the western countries, which may have a positive impact against the development of agoraphobia. In this study women were less likely than men to have PD with agoraphobia (17.8\% versus $20 \%$ ), this result disagrees with Yonkers et al study who found that women were more likely to have PD with agoraphobia (85\% versus $75 \%){ }^{32}$ This difference may be related to that the females in our study were mostly housewives $(74 \%)$ who are mostly homebound hence, they are less likely to develop anxiety and panic attack outside the home environment. In addition, Turgeon et al study showed lower agoraphobic avoidance behavior in men of western countries to be associated with their alcohol use, ${ }^{33}$ which is used less by men in our society. In this study the comorbidity rate of MDD in PD with or without agoraphobia was $61 \%$, in the form of Mild $(21.2 \%)$, Moderate $(33.9 \%)$ or Severe without psychotic features MDD $(5.9 \%)$, while no cases were found having Severe with psychotic features MDD . This comorbidity rate $(61 \%)$ is concordant with Felicia et al study in 2003 $(38.29 \%)^{31}$, and Kessler et al study national comorbidity survey in 1998 (43.4\%) ${ }^{14}$, with Rief et al study in 2004 (47.4\%), ${ }^{34}$ and with Miriam et al study, that this comorbidity may reach up to $65 \% .{ }^{35}$ In our study the comorbidity rate was relatively high, patients in our society as opposed to western countries, usually consult the psychiatrists at later stage of the illness after consulting many physicians and doing 
many investigations searching for an organic cause for their symptoms, and this may lead to the development of more comorbidity and complications. Comorbidity rate was higher in males $(68.9 \%)$ than females $(57.5 \%)$, which was concordant with Goodwin et al study in 2004 who showed that the risk was about $2-2.5$ more in males than females. ${ }^{36}$

\section{Conclusion}

The majority of patients with PD in our sample had a comorbid MDD. Therefore, early detection and management of PD is required to reduce the complications and improve patient's quality of life.

\section{References}

1. Abdullah G. Mohammed, Abdulmuttalib Al-Fikki. Panic disorder: Review of current status. Bull Kuwait Inst Med Spec 2003; 2:22-6.

2. Fadem B. Behavioral science in medicine. $1^{\text {st }}$ ed. Philadelphia, USA: Lippincott Williams and Wilkins; 2004. p. 228.

3. Narrow WE, Regier DA, Rae DS, Manderscheid RW, Locke BZ. Use of services by persons with mental and addictive disorders: findings from the National Institute of Mental Health Epidemiologic Catchment Area Program. Arch Gen Psychiatry 1993; 50:95-107

4. Shinoda N, Kodama K, Sakamoto T, Yamanouchi N, Takahashi T, Okada S, el.al. Predictors of 1year outcome for patients with panic disorder. Compr Psychiatry 1999; 40:39-43

5. Shinoda N, Kodama K, Sakamoto T, Yamanouchi N, Takahashi T, Okada S, el.al. Predictors of 1year outcome for patients with panic disorder. Compr Psychiatry 1999; 40:39-43

6. Yates W. Phenomenology and epidemiology of panic disorder. Annals of clinical psychiatry, 2009;21(2):95-102

7. Steiner TJ. Lifting the burden: the global campaign against headache. Lancet Neurol 2004; 3:204-5.

8. Kessler RC. Epidemiology of psychiatric comorbidity. In: Tsuang MT, Tohan M, Zahner GEP , eds. Textbook in psychiatric Epidemiology. New York, USA: John Wiley and Sons Inc; 1995. p.179-97.

9. Clayton, $P$. The comorbidity factor: establishing $t$ he primary diagnosis in patients with mixed symptoms of anxiety and depression. J Clin Psychiatry. 1990; 51:35-9.

10. Merikangas KR, Angst J, Eaton WW, Canino G, Rubio-Stipec M, Wacker $\mathrm{H}$ et al comorbidity and boundaries of affective disorders with anxiety disorders and substance misuse: results of an international task force. Br.J Psychiatry. 1996; 168:58-67.
11. Andrade L, Eaton WW, Chilcoat HD. Lifetime comorbidity of panic attacks and major depression in a population-based study: age of onset. Psychol Med 1996; 26:991-6

12. Reed V, Wittchen H-U: DSM-IV panic attacks and panic disorder in a community sample of adolescents and young adults: how specific are panic attacks? J Psychiatr Res 1998; 32:335-45

13. Kessler RC, Stang PE, Wittchen HU, Ustun TB, Roy-Byrne PP, Walters EE. Lifetime panicdepression comorbidity in the National Comorbidity Survey. Arch Gen Psychiatry 1998; 55:8018

14. Peter P, Byrne R, Stang Pet. Lifetime panicdepression comorbidity in the National Comorbid Survey. Association with symptoms, impairment course and help seeking. Br.J Psychiatry 2000; 76:229-35.

15. Faravelli C, Peterniti S, Scharpato A. A 5 years prospective naturalistic follow-up study of Panic Disorder. Compr Psychiatry 1995; 36:271-7.

16. Carpiniello B, Baita A, Carta MG. Clinical and psychosocial outcome of patients affected by panic disorder with or without agoraphobia: results from a naturalistic follow-up study. Eur Psych 2002; 17:394-8.

17. Lecrubier $Y$. The impact of comorbidity on the treatment of panic disorder. J Clin Psychiatry 1998; 59:11-4.

18. Markowitz JS, Weissman MM, Ouellette R, Lish JD, Klerman GL. Quality of life in panic disorder. Arch Gen Psychiatry 1989; 46:984-92

19. Molnar BE, Buka SL, Kessler RC. Child sexual abuse and subsequent psychopathology: results from the National Comorbidity Survey. Am J Pub Health 2001; 91:753-60.

20. Pine DS, Cohen JA. Trauma in children and adolescents: risk and treatment of psychiatric sequeale. Biol Psych 2002; 51:519-31.

21.Goodwin RD, Olfson M. Treatment of panic attack and risk of major depression in the community. Am J Psychiatry 2001; 158:1146-8.

22. Figgitt DP, McClellan KJ. Fluvoxamine. An updated review of its use in the management of adults with anxiety disorders. Drugs 2000; 60:925-54.

23. Mavissakalian MR, Ryan MT. Rational treatment of panic disorder with antidepressants. Ann Clin Psychiatry 1998; 10:185-95.

24. Bakker A, Spinhoven $P$, van Balkom AJ, van Dyck R. Relevance of assessment of cognitions during panic attacks in the treatment of panic disorder. Psychother Psychsom 2002; 71:15861.

25. Bakker A, Spinhoven $P$, van der Does AJ, van Balkom AJ, van Dyck R. Locus of control orientation in panic disorder and the differential effects of treatment. Psychother Psychsom 2002; 71:859.

26. Mood disorders. American Psychiatric Association: Diagnostic and Statistical Manual of Mental 
Association, 2000. $1^{\text {st }}$ ed. p. 345-428.

27. Battaglia, M, Bertella S, Bajo S, Binaghi F, Bellodi L. Anticipation of Age at Onset in Panic Disorder. Am J Psychiatry, 1998; 155(5):590-5.

28. Fleet RP, Marchand A, Dupuis G, Kaczorowski J, Beitman BD. Comparing Emergency Department and Psychiatric Setting Patients With Panic Disorder. Psychosomatics, 1998; 39(6):512-8.

29. Andrade L, WILLIAM W, Eaton, Chilcoat H. Lifetime Comorbidity of Panic Attacks and Major Depression in a Population-Based Study: Symptom Profiles. Br.J Psychiatry, 1994; 165: 363-9.

30. Felicia Romosan, Liana Dehelean, Monica Ienciu. Comorbidity of panic disorder with depression: clinical implications. TMJ 2003; 53:246-9.

31. Yonkers KA, Zlotnick C, Allsworth J, Warshaw M, Shea T, Keller M. Is the Course of Panic Disorder the Same in Women and Men?. Am J Psychiatry, 1998;155(5):596-602

32. Turgeon L, Marchand A, Dupuis G. Clinical Features in Panic Disorder With Agoraphobia: A Comparison of Men and Women. J Anxiety Disord 1998; 12(6):539-53.

33. Rief W, Nankea A, Klaibergb A, Braehlerb E. Base rates for panic and depression according to the Brief Patient Health Questionnaire: a population-based study. Journal of Affective Disorders, 2004; 82: 271-6.

34. Miriam A. Mosing, Scott D. Gordon, Sarah E. Medland, Dixie J. Statham, Elliot C. Nelson, Andrew C. Heath. Et al. Genetic and environmental influences on the comorbidity between depression, panic disorder, agoraphobia, and social phobia: a twin study. Depression and Anxiety 2009; 26:1004-11.

35. Goodwin RD, Fergusson DM, Horwood LJ. Panic attacks and the risk of depression among young adults in the community. Psychotherapy and Psychosomatics, 2004; 73(3): 158-65. 